\title{
3D SURVEYING AND MODELING OF ARCHAEOLOGICAL SITES - SOME CRITICAL ISSUES .
}

\author{
S. Gonizzi Barsanti ${ }^{\text {a, }}$, , F. Remondino ${ }^{\text {b }}$, D. Visintini ${ }^{\mathrm{c}}$ \\ ${ }^{a}$ Dept. of Mechanics, Politecnico di Milano, Milano, Italy- sara.gonizzi@ @olimi.it \\ b 3D Optical Metrology Unit, Bruno Kessler Foundation (FBK), Trento, Italy - remondino@ @fbk.eu \\ ${ }^{\mathrm{c}}$ Dept. of Civil Eng. and Architecture, Univ. of Udine, Udine, Italy - visintini@ uniud.it
}

Commission V, WG V/3

KEY WORDS: Photogrammetry, Laser Scanning, 3D Modelling, Survey, Archaeological Documentation.

\begin{abstract}
:
The goal of the reported project is to test and evaluate 3D surveying and modelling methods to document the remaining ancient byzantine city walls of the archaeological site of Aquileia in Friuli Venezia Giulia, Italy. The objectives are threefold: (1) to use 3D data to create maps, façades and sections that provide information useful for archaeological purposes such as the investigation of architectural construction techniques or construction phases, (2) to evaluate and compare photogrammetric and laser scanner data in order to identify the advantages and disadvantages of the two 3D surveying techniques for archaeological applications and needs and (3) to draw broader conclusions about the applicability of photogrammetry and laser scanning for documenting and analysing ancient walls within a particular set of environmental circumstances. The paper presents the employed 3D surveying techniques, the obtained $3 \mathrm{D}$ results and 2D products and some critical comments.
\end{abstract}

\section{INTRODUCTION}

For archaeological research, it is important to appropriately record, document, and survey artefacts and sites because an accurate and complete digital documentation is a prerequisite for further analysis and interpretation. One type of archaeological documentation is the so-called direct survey, which involves measuring in direct contact objects, or excavation units, for example, using a calliper or tape measure: a survey of this type is highly time-consuming and is not so accurate. A second type is related to the use of indirect techniques that make use of, for example, total stations, Global Navigation Satellite System (GNSS) and 3D optical instruments, which offer several advantages over the direct acquisition techniques: (i) the time used to perform the survey is much shorter and the accuracy is higher; (ii) they do not require contact measurements avoiding possible damages to archaeological objects; (iii), a wide range of low cost sensors and processing algorithms have recently become available (Remondino, 2011).

The digital 3D acquisition of objects and structures is generally performed by means of (i) passive techniques (image-based methods) such as photogrammetry (Remondino, El-Hakim, 2006), (ii) active sensors (range-based methods) such as laser scanner (Vosselman, Maas, 2010) or (iii) an integration of active and passive techniques (Lambers, et al., 2007; Grussenmeyer et al., 2008; Guidi et al., 2009; Al-kheder et al., 2009). The best and most appropriate technique depends on the object to be surveyed or the area to be examined, on the user experience, on the budget, on the time available and on the goals of the research. Photogrammetric surveys are typically cost-effective and time-efficient and are able to provide, simultaneously, for the necessary 3D geometry and texture, with accuracy values for each determined 3D point, although a known distance or some ground control points are necessary in order to derive metric 3D results. A simple consumer grade digital camera, calibrated using ad-hoc algorithms and procedures in the lab, can be used for the surveying and successive 3D modelling. On the other hand, active sensors, such as laser scanners, collect directly metric 3D point clouds of artefacts or sites that can afterwards be used to produce highly accurate and detailed 3D models. The use of laser scanners in the archaeological sites, however, is unusual because of the high costs of instruments.

In this paper, we present a research that compares the two different 3D surveying techniques for archaeological documentation needs. 3D models and 2D products are produced and presented critically comparing the employed software and instruments, reporting possible guidelines too.

\section{THE TEST SITE}

The Byzantine walls of Aquileia (Fig.1) were chosen as a test field as they have many unresolved questions and do not have an adequate topographical documentation that is required to carry out further research. In addition, the site has been recently investigated as part of an operation to clean-up the structures in preparation to reopen the site to the public. The walls probably belong to the last fortress of Aquileia that when built, divided the ancient city. While remains of the fortifications are visible on the ground and in the modern cadastral divisions in the western part of the city, it was Luisa Bertacchi, in the 1960s (Bertacchi, 2003), who recognized the path of the walls and realized that it was the same structures documented by the Austrians in 1871-1872 and which are correlated to the river harbour, excavated by Giovanni Brusin in the southern part of the city. The city walls are located in the NW part of Aquileia and are generally dated to the end of the fifth century AD or to the middle part of the sixth century AD. These dates were determined by a study of the masonry technique that identified a technical element that appears, for example, in the mortar of the walls the baptistery of Elijah in Grado, from the second half of sixth century, but is already present in the Byzantine walls of Leptis Magna, built after the Justinian's recapture (post 533 A.D.). It also appears in the tomb of St. Peter under the Vatican Basilica, also dating back to Byzantine times (Buora, 2009). 


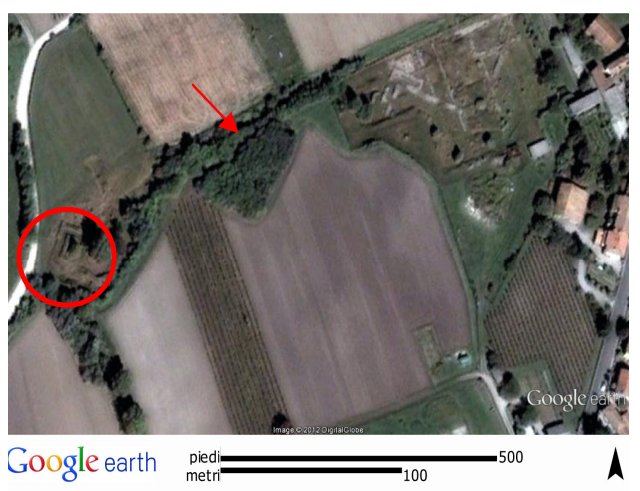

Figure 1. The position of the archaeological area in Aquileia close to the ancient city walls.

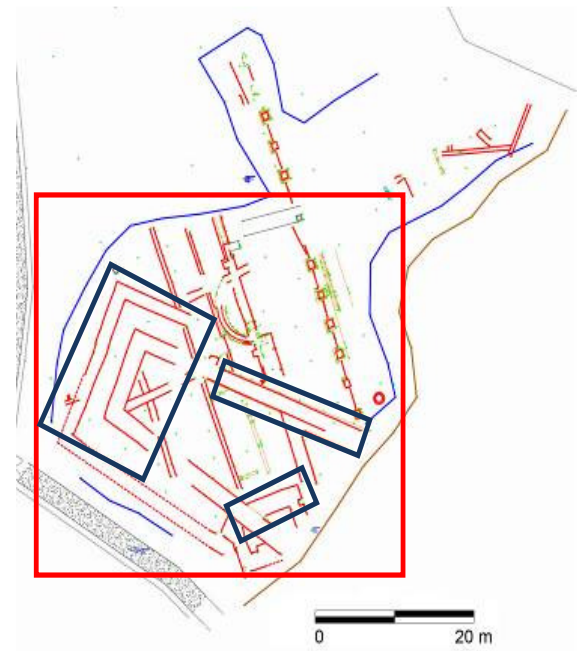

Figure 2. The site sketch produced from a total station survey showing the areas surveyed with UAV and TLS laser scanner (red) as well as with photogrammetry (blue).

\section{DATA COLLECTION}

The starting point of the work in Aquileia was the collection of both photogrammetric and laser scanner data of the site. First, a survey was made with a Topcon $3005 \mathrm{~N}$ total station to acquire ground control points to geo-reference and bring the two models into a common reference system. Second, a laser scanner survey was made on the entire site. Third, two types of photogrammetric data were collected: (1) an Unmanned Aerial Vehicle (UAV) survey collected data for the entire site; (2) a terrestrial photogrammetric survey was used only on a sub-set of walls that were in an ideally-suited (standing with no or few presence of grass, etc.) for 3D modelling purposes (Fig.2).

\subsection{Range data acquisition}

To collect range data, a Leica HDS 7000 laser scanner was used. Based on TOF measuring principle, this scanner allows a wide field of view $\left(360^{\circ} \mathrm{H} \mathrm{x} 320^{\circ} \mathrm{V}\right)$ and the acquisition of max of 1 million points per second with mill metric resolution and accuracy. In total, 22 scans were performed, resulting in a dataset of ca. 96 million points (Tab. 1). The first seven scans, captured an external perspective of the site, used collected data at a distance of $10 \mathrm{~m}$ to achieve a sampling test of $3.1 \mathrm{~mm}$. The remaining fifteen scans captured data inside the site in order to acquire more details of the structures, and collected data with an average sampling distance of $12.6 \mathrm{~mm}$. These values were chosen as an acceptable compromise between level of detail of the final 3D model and computing resources needed for data processing. The laser scanner data were used (i) as metric reference to scale the image data, (ii) for a geometric comparison with the photogrammetric data and (iii) for the creation of archaeological sections of the site.

\begin{tabular}{|c|c|c|}
\hline & Dataset 1 & Dataset 2 \\
\hline Number of scans & 7 & 15 \\
\hline Geometric resolution & $3.1 \mathrm{~mm} \mathrm{@}$ & $12.6 \mathrm{~mm} @$ \\
& $10 \mathrm{~m}$ & $10 \mathrm{~m}$ \\
\hline Num. of acquired points & ca. 84 millions & ca. 75 millions \\
\hline Num. of final polygons & \multicolumn{2}{|c|}{ ca 127 millions } \\
\hline
\end{tabular}

Table 1. Comparison of the two different datasets acquired with the laser scanner and the total number of polygons after the geometric processing.

\subsection{Photogrammetric data acquisition}

The terrestrial photogrammetry technique was applied only to some walls. A calibrated Canon 60D camera was used. The camera features 18 megapixel camera with a $22.3 \times 14.9 \mathrm{~mm}$ CMOS sensor coupled with an 18-200 mm lens. Approximately 400 images were acquired in three surveys carried out in three different months: the first in January, the second in March and the third in May 2012. The images were acquired keeping the camera at the minimum focal length $(18 \mathrm{~mm})$, while the image resolution was set at the highest level (5138 x 3456 pixels) in order to acquire good quality textures. The distance to which the images were taken is variable $(2-5 \mathrm{~m})$ due to the articulation of the archaeological site. In some cases, it was not possible to stand more than $2 \mathrm{~m}$ from the wall. The images were taken both convergent and nadir, and the overlap is about $40 \%$ (Fig.3).
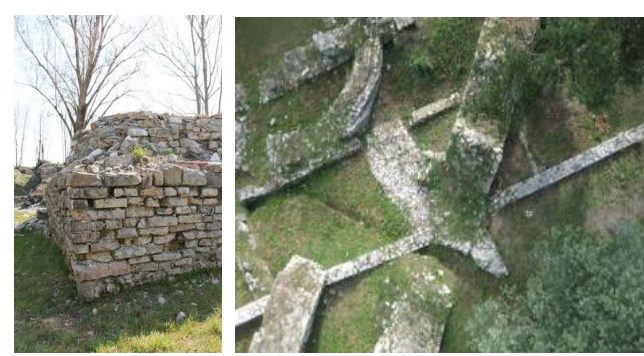

Figure 3. Example of images acquired for terrestrial photogrammetric surveying and using the UAV platform.

The UAV survey was performed with the Quad copter Gaui 300X-S that weighs about 400 grams without batteries. The maximum payload is around 700 grams. A Canon IXUS 85 IS (35 mm focal length) was mounted on board, the image resolution was set at $3648 \times 2736$ pixels, and about 150 images were acquired (Fig.3). The UAV did not have any GNSS or INS on-board and it was manually piloted leading to a flight altitude variable between 15 and $25 \mathrm{~m}$. Given the characteristics of the quad copter used, which, as seen, has a payload of 700 grams maximum, it has been used a compact camera. The choice on the brand has been dictated by the possibility that most of the Canon have to use open source software, CHDK, which allows many applications to be added to the camera.

The software gets loaded into the camera's memory upon boot up, either manually or automatically, using the microprocessor that controls the camera and it performs no actual change on the camera. For this project the software was used for providing the opportunity to shoot in sequence with an interval time of 5 
seconds, from remote: this function was useful for shots from the quad copter because in this way it was enough to activate the program and, during the flight, the camera continuously took photos without the intervention of the operator that could be difficult in a totally manual flight. The aim of the UAV data is to create an overview orthoimage of the site and produce and up-to-date map.

\section{DATA PROCESSING}

The collected images and range data were processed independently as reported below.

\subsection{D model generation from photogrammetric data}

The UAV data processing and a sub-set of the terrestrial images (56) were used for the 3D modelling of the site and walls, respectively. The average ground sample distance (GSD) of the UAV images is approximately $6-8 \mathrm{~mm}$ while terrestrial images have a GSD of $5 \mathrm{~mm}$. The image data were processed with two different packages:

- Visual SfM (Fig.4-left) is an automated software. The tool is essentially a black box that automatically processes the imported images without permitting users any interaction or editing. This software is a GUI application of Structure from Motion (SfM) algorithms.

- Agisoft Photoscan (Fig.4-right) is a commercial tool able to create 3D models from still images. Both image alignment and 3D model reconstruction are fully automated with some small user interaction allowed. The results are quite dense and complete and it also offers the possibility to create orthoimages.

The results clearly show the problems of (most) SfM tools as also shown in Remondino et al. (2012).

\subsection{D model generation from laser scanner data}

In order to process the laser scanning data, the range data were cleaned, aligned, meshed and edited using Cyclone, Geomagic Studio and Polyworks as each of them has limitations in some processing functions. The problem of the non-compatibility of the extensions of the laser scanner file is something that has not
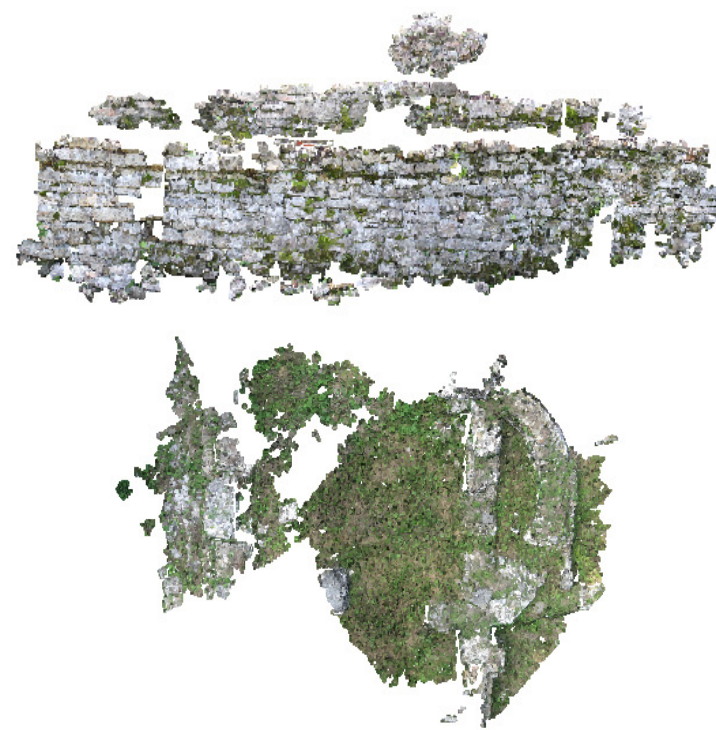

been solved yet. Each brand/instrument has its own file extension and a specific software to work with, so every time you have to deal with files coming from different laser scanner it's always necessary to convert them, using different tools. Another bottleneck of the range-based data processing pipeline is the long editing / working time: all the process for generating a completed and suitable polygonal model for other uses is really time consuming. It took several days to clean the point cloud, register all the scans, create the mesh and at the end have the 3D model with all the holes filled, ready to use. In addition, usually the $3 \mathrm{D}$ model is heavy, even with a decimation of the triangles, and a computer or a laptop with medium characteristics are not suitable to manage large datasets. Last but not least, a good texture is normally missing, requiring texture mapping procedures to map high resolution images onto the range-based 3D geometry.

Nevertheless a laser scanner instrument is very easy to be used, a 3D data from laser scanner data are very useful because as accurate and often detailed, the derived geometric models are the exact/metric copy of the original object and different analyses and studies can be performed.

\section{USE OF 3D DATA FOR ARCHAEOLOGICAL DOCUMENTATION AND DELIVERABLE}

The 3D data from both techniques were used as a support for the documentation of the archaeological site. The technologies and methodologies in the service of digital recording of archaeological sites and objects are becoming increasingly important. 3D modelling can be extremely significant in the identification, monitoring, conservation and restoration of sites, buildings and objects (Gruen, 2008).

At a landscape scale, 3D digital modelling and the subsequent data analysis allow archaeologists to integrate different elements and document the area. At the level of the archaeological site or monument, the 3D makes it possible to obtain accurate and objective documentation as well as a new point of view for the analysis of the state of a structure for subsequent diagnosis or restoration. At the level of artefact, finally, 3D modelling allows to get a true, accurate replica of the object, both digital and physical thanks to the use of 3D printers, so that is possible to study any artefact, measure it, restore it and show it to the public.
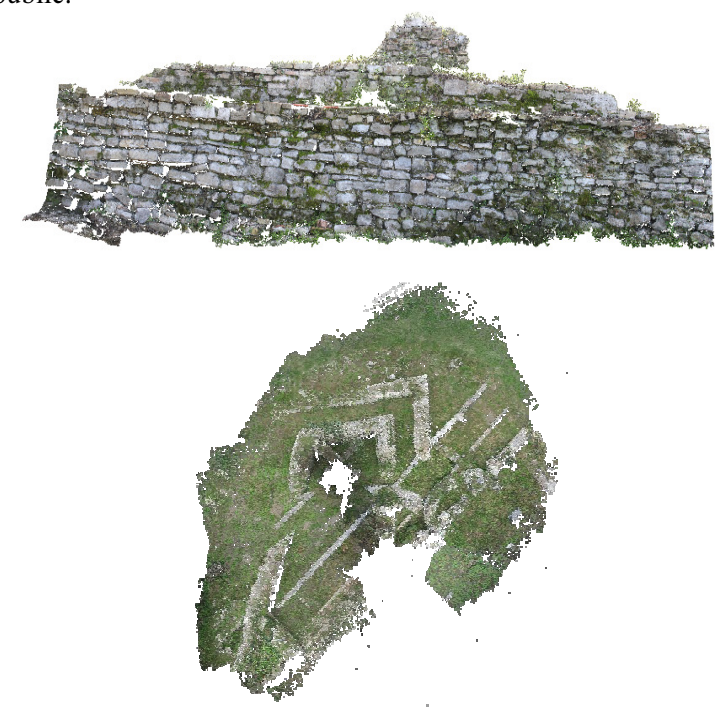

Figure 4. VisualSfM (left) and Agisoft (right) results for the wall and UAV images. Visible holes and non-reconstructed areas are present in the SfM tool. 
5.1

\section{Terrestrial photogrammetry data}

For the morphology of the site and its complexity and due also to the bad condition of the structures, it was decided to use terrestrial photogrammetry only to document some specific walls, the ones which were interesting for certain archaeological analysis, such as restorations, collapses, integrations. As seen, two different software were used and compared, Agisoft Photoscan and VisualSfM. The results of the processing were compared with the laser scanner data and then to each other (Fig. 6), to determine which one could be useful for archaeological purposes. The scale used for the comparison is equal to the GSD of the photogrammetric data. The models were scaled using a calibrated bar.
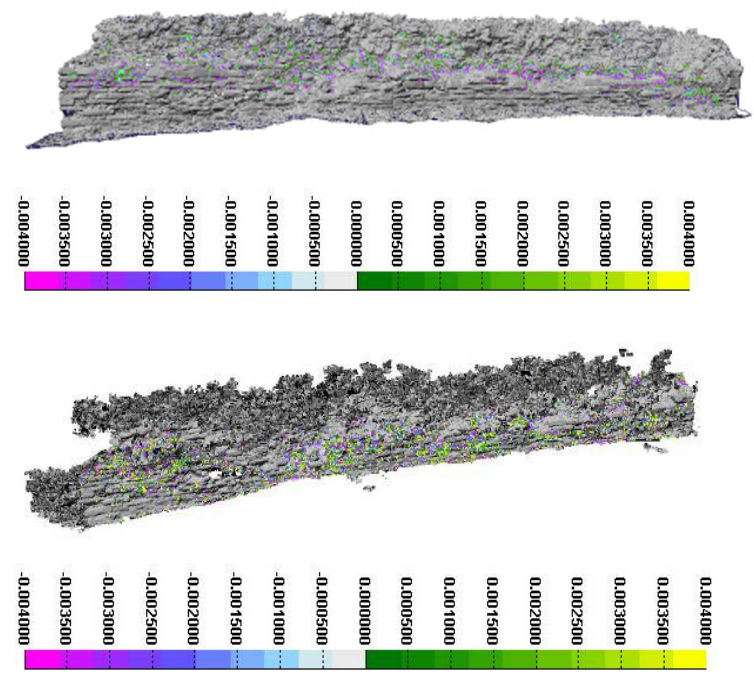

Figure 6 . The comparison $[\mathrm{m}]$ of a wall between the model derived from Agisoft Photoscan (above) and Visual SfM (below) and the TLS data.

Compared with the laser scanner data, both the models showed some incongruences, but while in the Photoscan's model they are located mostly in the upper part of the wall, where the mesh had holes and gaps due to the impossibility of making the images from a higher position, in the Visual's model they are visible in different part of the wall. The discrepancies for Agisoft were between $-4 \mathrm{~mm}$ and $+2 \mathrm{~mm}$ while VisualSfM gave $\pm 4 \mathrm{~mm}$. The two mesh were compared also to each other (Fig.7) showing some differences between them: the data obtained with VisualSfM diverged from the other about $-4 \mathrm{~mm}$ and also the geometry is a little more inaccurate in some part (upper and left parts).

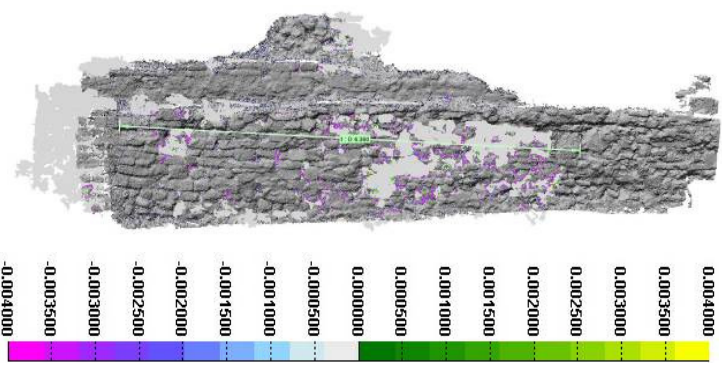

Figure 7. The comparison [m] between the mesh derived with Agisoft and the one from VisualSfM.
After these tests it was decided to use Agisoft for the 3D documentation of the walls, also due to its capability to create othoimages from the 3D model. This documentation was useful to create façade digitisations in Autocad, useful to identify later restorations, fractures and integrations. From these data a map with all the different phases of the history of the walls could be drawn (Fig.8). These façades are useful because the data derived from photogrammetry are accurate and is possible in this way to control the preservation of the walls, to identify the modern restoration in order to map the original part of the structure, to highlight the fractures or integration to create a phase map. All these data are important tools for the protection of the site and for future intervention of conservation.
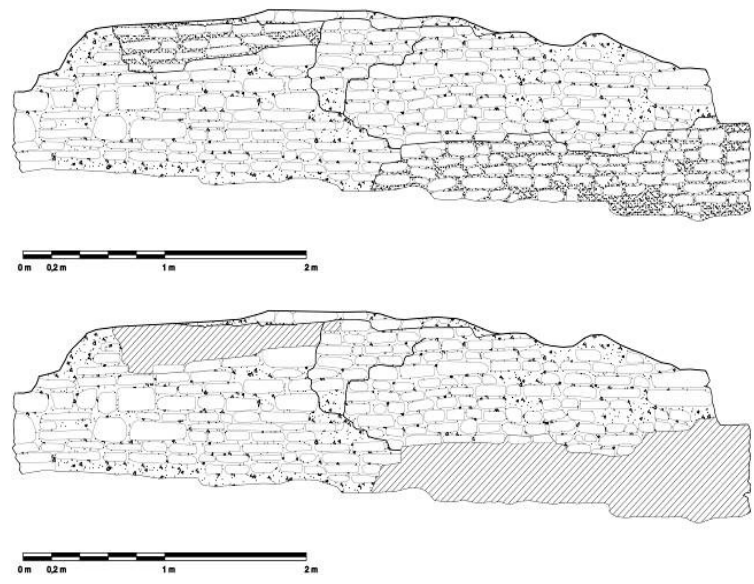

Figure 8. The digitalization results of a wall showing restorations and the fractures (lower image).

\subsection{UAV data}

The data (ca 150 images) were processed with Agisoft Photoscan producing an orthoimage at $2.5 \mathrm{~cm}$ resolution (Fig.10a). The photogrammetric project was georeferenced and scaled using the total station survey data. The orthoimage was used to digitize a plan of the site and to highlight the different visible phases (Fig. 10b, 10c). The site is composed of three main phases: the older, in blue in the image, is probably a warehouse or a public building, the second in time is the red one - a tower related to the first defensive buildings of the city and the latter, in yellow, is the phase related to the Byzantine city walls.

\subsection{Laser scanner data}

The data from laser scanner was used as reference for a comparison with the photogrammetric data and as documentation for the creation of sections of the archaeological site (Fig. 11). It was decided to use these data because they were the most complete covering of the entire site (indeed the UAV data created an hole in the final orthoimage). For the creation of the sections, Polyworks and Autocad were used. In this way the documentation is complete, accurate and detailed and it's possible to analyse the differences in height of the various structures but also to identify the construction techniques of the walls. 


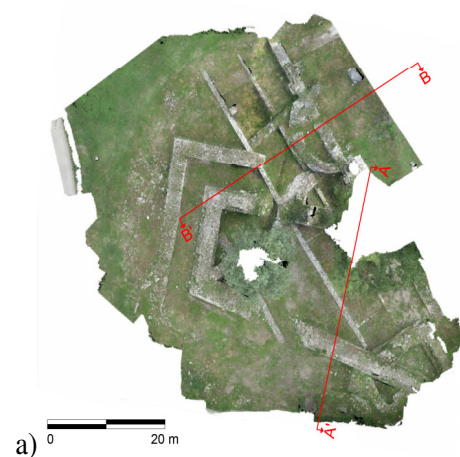

a)

Figure 10. The orthoimage produced from the UAV images with highlighted (AA', BB') the produced archaeological sections (a). The site plan created integrating the orthoimage and the topographic survey (b). The three different construction phases highlighted on the map (c).

\section{CONCLUSIONS}

Using reality-based 3D surveying and modelling it is possible to derive metric data useful for archaeological investigations. Anyway, for both approaches, the modelling part (from point cloud to surface) is still rich of problems and often the most time consuming part of the work. The documentation that can be derived from the $3 \mathrm{D}$ surveyed and modelled data is various: plans, sections and façades, useful for further investigations of the site and for conservation and preservation policies. Using metric 3D data, the 2D products are accurate and precise and it's possible to extract exact measurements, the total area of the restorations and of the missing parts. It takes a long time processing to have comfortable data to use but the results are the most accurate is possible to have. Some examples include the generation of orthoimages, detailed site maps, sections for ancient walls and segmented high-resolution 3D models to identify construction techniques, sequences, restorations, etc. Textured 3D models of archaeological sites are also useful for visualization purposes to engage the public and assist archaeologists in interpretations of past uses of space.

Photogrammetry requires experience and images have to be properly acquired, otherwise the results are not satisfactory, in particular with fully automated black-boxes tools. New fully automated methods (based on Structure from Motion techniques) are getting quite popular in the archaeological field but metrics and reliability of such approaches are still very far away from being a successful solution. One of the problems of the models produced with photogrammetry is scaling them in a proper way, in order to have an accurate and precise model. It can be used a metric reference on the images but not always it's visible in the model, or the total station's points or the laser scanner data. It's anyway important to have different references to control the right scaling of the mesh.

Laser scanning, on the other hand, is not so difficult to be used during the surveying, but it requires a lot of time and experience during the processing in the lab. Moreover, the data are usually difficult to deal with because of the heaviness of the models that are composed by a high number of polygons, especially for large site or buildings. This kind of data are quite impossible to be visualized in a normal laptop and require a high performance desktop computer to open and process them. The choice of the technique depends on different factors and it is often strictly related to the budget of the project. Both surveying techniques have their advantages and disadvantages (Tab. 2). Several recent publications compared the two technologies based on

\begin{tabular}{|c|c|c|}
\hline & $\begin{array}{c}\text { Photogrammetry } \\
\text { (Image-based } \\
\text { modelling) }\end{array}$ & $\begin{array}{c}\text { Laser Scanning } \\
\text { (Range-based } \\
\text { modelling) } \\
\end{array}$ \\
\hline \multicolumn{3}{|l|}{ Characteristics } \\
\hline $\begin{array}{c}\text { Cost of the } \\
\text { instruments (HW } \\
\text { and SW) }\end{array}$ & Low & High \\
\hline $\begin{array}{l}\text { Manageability / } \\
\text { Portability }\end{array}$ & Excellent & Sufficient \\
\hline $\begin{array}{c}\text { Time of data } \\
\text { acquisition }\end{array}$ & Quite short & Generally long \\
\hline Time for modelling & $\begin{array}{c}\text { Short but } \\
\text { experience required }\end{array}$ & Often long \\
\hline 3D information & To be derived & Direct \\
\hline $\begin{array}{c}\text { Distance's } \\
\text { dependence }\end{array}$ & Independent & Dependent \\
\hline $\begin{array}{c}\text { Dimension's } \\
\text { dependence }\end{array}$ & Independent & Dependent \\
\hline $\begin{array}{c}\text { Material's } \\
\text { dependence }\end{array}$ & $\begin{array}{c}\text { Almost } \\
\text { independent }\end{array}$ & Dependent \\
\hline Light's dependence & Dependent & $\begin{array}{c}\text { Almost/totally } \\
\text { independent }\end{array}$ \\
\hline $\begin{array}{l}\text { Geometry's } \\
\text { dependence }\end{array}$ & Quite dependent & Independent \\
\hline $\begin{array}{c}\text { Texture's } \\
\text { dependence }\end{array}$ & Dependent & Independent \\
\hline Scale & Absent & Implicit (1:1) \\
\hline Data volume & $\begin{array}{l}\text { Dependent on the } \\
\text { images resolution } \\
\text { and on the } \\
\text { measurements }\end{array}$ & $\begin{array}{l}\text { Dense point } \\
\text { cloud }\end{array}$ \\
\hline Detail's modelling & Good/excellent & $\begin{array}{r}\text { Generally } \\
\text { excellent }\end{array}$ \\
\hline Texture & Included & $\begin{array}{c}\text { Absent/Low } \\
\text { resolution }\end{array}$ \\
\hline Edges & Excellent & $\begin{array}{c}\text { Quite } \\
\text { problematic }\end{array}$ \\
\hline Statistics & For each 3D point & Global \\
\hline $\begin{array}{l}\text { Open-source } \\
\text { software }\end{array}$ & Many & A few \\
\hline
\end{tabular}

Table 2. Synthesis of photogrammetry and laser scanning techniques and characteristics. 
factors such as accuracy and resolution. We argue that both technologies are capable of providing similar accuracy and resolution when supported by a well-designed digitisation plan. Thus, before selecting between the two, one must determine the design parameters for each technique to match the required accuracy and resolution. In case of complex sites, a good solution still seems to be the combination of the methods, as each one has attributes and elements balancing the other one and in order to: (i) use the fundamental strengths of each technique, (ii) make up for weaknesses of the methods, (iii) obtain different geometric Levels of Detail (LoD) of the scene and (iv) achieve more accurate and complete geometric surveying for modelling, understanding, representation and digital conservation issues. The last problem is related to the automation of the processes with the new available software (expecially SfM). Automated and reliable procedure for the extraction of image correspondences and photo-triangulation are already accessible, but most of the approaches for the extraction of the architectural and archaeological data are still based on manual / interactive measurements, as more reliable and accurate, in particular at production level. It's important to understand how accurate can be a model derived from an automatic software in relation to the final use of it (study, documentation, visualization, etc.).

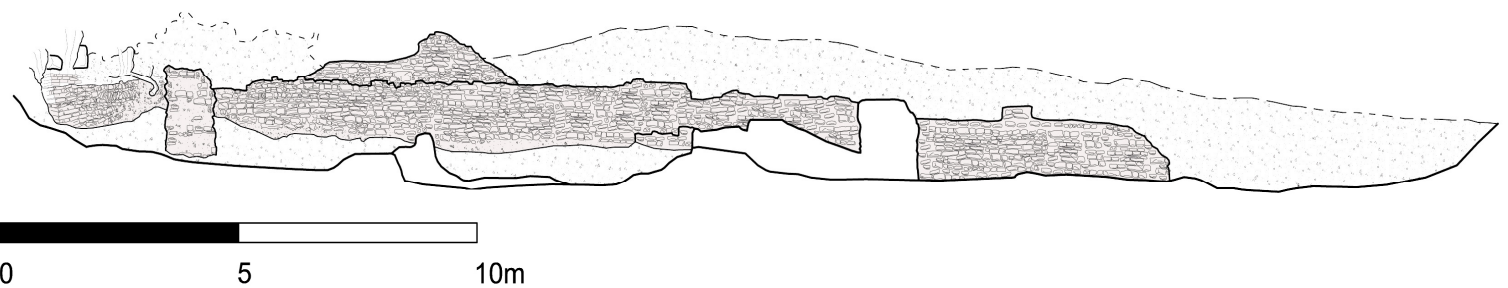

0

5

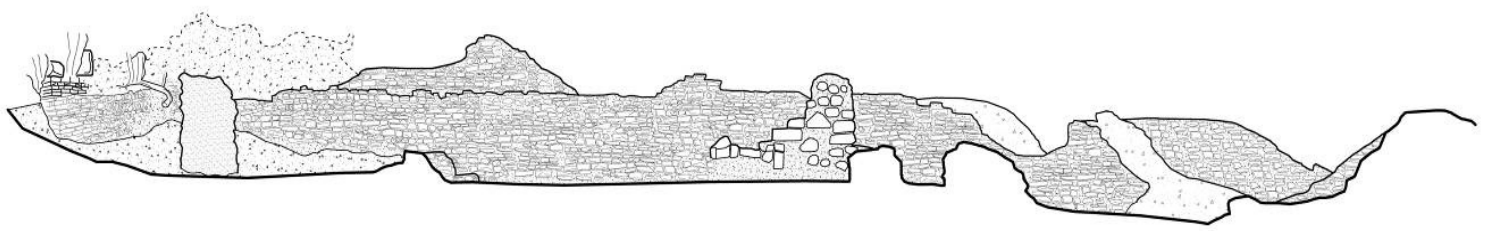

0 5 $10 \mathrm{~m}$

Figure 11. Two sections (AA', BB') of the archaeological area derived from the laser scanning surveying.

\section{ACKNOWLEDGEMENTS}

The authors want to thank Dr Luigi Fozzati and Dr Paola Ventura of the Soprintendenza per i Beni Archeologici del Friuli Venezia Giulia (Italy), for giving the possibility to use the archaeological site as a test field, as well as Dr Massimo Lavarone who is managing the operation of cleaning and the arrangement of the site.

\section{REFERENCES}

Al-kheder, S., Al-shawabkeh, Y., Haala, N., 2009. Developing a documentation system for desert palaces in Jordan using 3D laser scanning and digital photogrammetry. Journal of Archaeological Science, Vol. 36(2), pp. 537-546.

Bertacchi L., 2003. Nuova pianta archeologica di Aquileia. Udine

Buora, M., 2009. Intorno ad Attila. Dal mondo dei simboli alla realtà dell'archeologia (e viceversa). Archeologia omo e territorio, Rivista scientifica del volontariato archeologico, Vol. 28, 3-16.

Gruen, A., 2008. Reality-based generation of virtual environments for Digital Earth. International Journal of Digital Earth, Vol. 1, pp 88-106.

Grussenmeyer, P., Landes, T., Voegle, T., Rongle, K., 2008. Comparison methods of terrestrial laser scanning, photogrammetry and tacheometry data for recording of cultural heritage buildings. Inter. Archives of Photogrammetry, Remote
Sensing and Spatial Information Sciences, Vol. 37(B5), pp. 213-218.

Guidi, G., Remondino, F., Russo, M., Menna, F., Rizzi, A., Ercoli, S., 2009. A Multi-Resolution methodology for the 3D modelling of large and complex archaeological areas. International Journal of Architectural Computing, Vol. 7(1), pp. 39-55.

Lambers, K., Eisenbeiss, H., Sauerbier, M., Kupferschmidt, D., Gaisecker, T., Hanusch, T., 2007. Combining photogrammetry and laser scanning for the recording and modelling of the Late Intermediate Period site of Pinchango Alto, Palpa, Peru. Journal of Archaeological Science, Vol. 34(10), pp. 1702-1712.

Remondino, F., Del Pizzo, S., Kersten, T., Troisi, S., 2012. Low-cost and open-source solutions for automated image orientation - A critical overview. Proc. Euromed 2012, LNCS 7616, pp. 40-54. Springer, Heidelberg.

Remondino, F., 2011. Heritage Recording and 3D Modelling with Photogrammetry and 3D Scanning. Remote Sensing, Vol. 3, pp. 1104-1138.

Remondino, F., El-Hakim, S., 2006. Image-based 3D Modelling: a Review. Photogrammetric Record, Vol. 21(115), pp. 269-291.

Vosselman, G., Maas, H.G., 2010. Airborne and Terrestrial Laser Scanning. CRC Press. 